\title{
PENGARUH MUSIK KLASIK TERHADAP REGULASI EMOSI TUNADAKSA DI YPAC SURAKARTA
}

\author{
Sugeng Haryadi dan Novela Nadia Fardah \\ Jurusan Psikologi Fakultas Ilmu Pendidikan Universitas Negeri Semarang
}

\begin{abstract}
Different physical with normal people make children more sensitive physical disability. Physical disability child tends to feel shame, low self-esteem and sometimes appear selfish attitude towards the environment especially when under pressure because of mental disability, failure to manage these emotions can make aggressive and apathetic. The objective of this research was to determine the effect of classical music on emotion regulation physical impairment in YPAC Surakarta. This research is experimental research design using one-group pretest-posttest design. Subjects were physical disability YPAC Surakarta aged 12-16 by 10 students. Methods of data collection in this study using psychological scales are scales of emotion regulation as much as 24 item. Data analysis using statistical testing techniques Non Parametric Wilcoxon Signed Ranks yield sig of 0.025 , the value of $Z$ score of -2.809 and a mean rank of 0.00 at pretest posttest whereas at 5.50. It can be concluded that there are changes in emotion regulation significantly between pretest and posttest experimental group after being given treatment in the form of classical music.
\end{abstract}

Key words: classical music, emotion regulation, physical disability

\begin{abstract}
Abstrak
Fisik yang berbeda dengan orang normal membuat anak tunadaksa lebih sensitif. Anak tunadaksa cenderung merasa malu, rendah diri dan kadang muncul sikap egois terhadap lingkungannya apalagi jika mendapat tekanan psikis karena kecacatan tersebut, kegagalan mengolah emosi tersebut dapat membuat agresif dan apatis. Tujuan yang ingin dicapai dalam penelitian ini adalah untuk mengetahui pengaruh pemberian musik klasik terhadap regulasi emosi tunadaksa di YPAC Surakarta. Penelitian ini merupakan penelitian eksperimen yang menggunakan desain penelitian one group pretest-postest design. Subjek penelitian adalah anak tunadaksa YPAC Surakarta yang berusia 12-16 tahun sebanyak 10 siswa. Metode pengumpulan data dalam penelitian ini menggunakan skala psikologi yaitu skala regulasi emosi sebanyak 24 item. Analisis data menggunakan teknik uji statistik Non Parametric Wilcoxon Signed Ranks menghasilkan nilai sig sebesar 0,025, nilai Z skore $-2,809$ dan mean rank pada saat pretest sebesar 0,00 sedangkan posttest sebesar 5,50. Dapat diambil simpulan bahwa ada perubahan regulasi emosi yang cukup signifikan antara pretest dan posttest kelompok eksperimen setelah diberi perlakuan yang berupa memperdengarkan musik klasik.
\end{abstract}

Kata-kata kunci: musik klasik, regulasi emosi, tunadaksa

$\mathrm{M}$ anusia ingin terlahir sempurna sesuai dengan apa yang diharapkan, karena manusia yang lahir dalam keadaan sempurna tak pernah menginginkan dirinya menjadi manusia yang cacat, entah itu cacat mental maupun cacat fisik. Hidup sebagai orang yang berkondisi fisik sempurna sering mengalami banyak kesulitan dalam kesehariannya, apalagi jika orang itu mengalami kecacatan. Kecacatan dapat terjadi 
pada orang dewasa maupun anak-anak, dan dalam hal ini anak yang memiliki kecacatan atau penyandang cacat sering disebut sebagai anak berkebutuhan khusus.

Beberapa tahun terakhir jumlah anak berkebutuhan khusus di Indonesia terus meningkat. Jumlah anak berkebutuhan khusus pada tahun 2012 sebesar 0,7\% dari jumlah penduduk Indonesia, atau sekitar 1.544.184, yang termasuk usia sekolah 5-18 tahun sebesar $21,42 \%$ atau 330.764 anak. Dari jumlah tersebut hanya 85.737 anak berkebutuhan khusus yang sekolah, artinya masih terdapat 245.027 anak berkebutuhan khusus yang belum mengenyam pendidikan di sekolah khusus ataupun inklusi. Hasil survei Badan Koordinasi Pendidikan Luar menyebutkan bahwa di Jawa Tengah terdapat 246.675 anak berkebutuhan khusus, yang mendapatkan pendidikan hanya 9.867 atau $4 \%$ dari jumlah anak berkebutuhan khusus, dan selebihnya yaitu 236.808 belum mendapatkan pendidikan. Jumlah tunadaksa di Indonesia tidak terlalu banyak, akan tetapi jumlah tunadaksa di propinsi Jawa Tengah yang mendapatkan pendidikan hanya 105 anak dan Jawa tengah merupakan propinsi yang memiliki jumlah tunadaksa terbanyak di Indonesia.

Usaha untuk mengembangkan pendidikan telah diupayakan oleh pemerintah dengan sebaik mungkin, akan tetapi anak berkebutuhan khusus tetap berbeda dengan anak normal, begitu pula dengan anak tunadaksa yang memiliki kelainan fisik. Oleh karena itu, anak tunadaksa pun membutuhkan perhatian yang lebih, karena pendidikan untuk tunadaksa harus mencakup dua hal, yaitu pengembangan kondisi fisik dan psikis anak. Pengembangan kondisi fisik terdiri dari keadaan fisik anak, kemampuan melakukan kegiatan sehari-hari, kemampuan koordinasi yang disesuaikan dengan tingkat kecacatan, sedangkan untuk pengembangan kondisi psikis terdiri dari inteligensi, sikap dan kehidupan emosional, kepribadian anak, bakat, minat, hobi dan cita-cita. Namun, pelaksanaan pendidikan untuk anak tunadaksa selama ini hanya bertujuan pada pengembangan fungsi fisik, padahal dalam proses pembelajaran tidak hanya fungsi fisik yang penting, akan tetapi keadaan psikologis anak pun harus dijaga dengan baik, salah satunya adalah kehidupan emosional, karena keadaan mental dan emosi anak didik dapat menghambat atau mendorong belajar dan prestasi anak di sekolah.

Setiap manusia mengalami berbagai macam peristiwa yang melibatkan emosi. Manusia akan malu dan marah ketika diremehkan dihadapan umum, menangis karena sedih, melompat kegirangan karena memenangkan perlombaan, tersenyum karena mendapatkan penghargaan dan masih banyak emosi yang lain, begitu pula penyandang tunadaksa yang merasakan berbagai macam emosi. Walaupun manusia normal dan penyandang tunadaksa dapat merasakan emosi, akan tetapi penyandang tunadaksa lebih sensitif terhadap stimulus-stimulus emosi dibandingkan dengan orang normal, hal itu terjadi karena penyandang tunadaksa memiliki kekurangan yang terlihat jelas dibandingkan dengan orang normal. Karena memiliki perasaan yang lebih sensitif maka penyandang tunadaksa memerlukan kemampuan regulasi emosi agar lebih mudah dalam melakukan penyesuaian sosial.

Adanya fenomena kurangnya kemampuan siswa dalam meregulasi emosi ditunjukkan dalam observasi yang dilakukan peneliti pada bulan Mei tahun 2012 terhadap tujuh siswa YPAC Surakarta menunjukkan bahwa lima dari tujuh siswa masih merasa kesulitan dalam mengontrol emosinya sehingga emosi yang muncul meluap-luap dan tidak sesuai dengan situasi dan kondisi yang ada. Adanya beberapa masalah emosi yang dialami menunjukan bahwa penyandang tunadaksa di YPAC Surakarta perlu mendapatkan perhatian lebih sehingga para penyandang tunadaksa dapat mengatur, mengevaluasi, memodifikasi dan dapat mengomunikasikan perasaannya dengan tepat atau sering disebut sebagai regulasi emosi.

Lingkungan dan kognisi manusia mempengaruhi kemampuan regulasi emosi individu, dimana ketika individu berada di situasi yang positif maka, kognisi manusia akan melakukan pemrosesan stimulus dengan 
benar, sehingga emosi yang akan muncul akan menjadi positif . Berdasarkan penelitian Utami (2003 : 25) ditemukan bahwa "musik klasik mampu menciptakan suasana fisik yang tenang, karena musik klasik mampu menghadirkan irama dan keindahan bunyi yang menghanyutkan.”

Djohan (2009 : 87) berpendapat bahwa "musik mempunyai kekuatan untuk mengantar dan menggugah emosi." Djohan (2009 : 86) menambahkan "mendengarkan musik dapat merangsang atau menstimulasi respon emosi yang dalam istilah terapi disebut sebagai aktifnya berbagai perasaan." Musik secara efektif dapat menjadi fasilitator dan katalisator dalam mendorong individu untuk mengalami dan mengekspresikan perasaan-perasaan dan dengan mendengarkan musik maka emosi kita akan terpengaruh. Oleh karena itu peneliti akan memberikan perlakuan berupa musik klasik untuk meningkatkan regulasi emosi tunadaksa.

Regulasi emosi tunadaksa adalah kemampuan yang dimiliki anak tunadaksa untuk mengatur, mengevaluasi, memodifikasi dan dapat mengkomunikasikan perasaan emosional dengan tepat, dimana terdapat proses instrinsik dan ekstrinsik yang mendasarinya.

Aspek-aspek regulasi emosi : (1). Pemilihan situasi yaitu tindakan menghindari atau mendekati objek tertentu untuk mempengaruhi emosi. (2). Modifikasi situasi mengubah atau memodifikasi situasi (lingkungan eksternal) untuk mengubah pengaruh emosi. (3). Penyebaran perhatian yaitu perhatian terhadap situasi yang mempengaruhi emosi dimana individu menyadari dan memahami keseluruhan proses yang terjadi didalam dirinya, perasaanya, pikirannya dan latar belakang tindakannya sehingga tunadaksa mampu melakukan fokus terhadap hal-hal yang menyenangkan. (4). Perubahan kognisi yaitu mengubah cara berpikir tentang situasi atau kemampuan dalam mengatur emosi yang dilakukan dengan pemaknaan terhadap situasi tersebut yang dilanjutkan dengan pemilihan makna. (5). Modulasi respon merupakan tindakan mengubah respon yang sebelumnya akan dilakukan terhadap situasi yang terjadi dengan suatu respon baru.

Musik klasik adalah musik yang berasal dari Eropa sekitar tahun 1750-1825 dimulai dengan komposer Haydn dan Mozart yang memiliki tingkat kesulitan dari segi harmoni, melodi atau komposisinya. Musik Haydn dengan tempo yang tidak terlalu lambat dengan 62-70 beat per menit digunakan untuk meningkatkan tingkat energi emosi positif sedangkan musik Mozart yang memiliki tempo lambat dengan 54-62 beat per menit digunakan untuk menurunkan tingkat energi emosi negatif. Adapun menu musik klasik yang akan diperdengarkan antara lain:

1) Sonata in $\mathrm{C}$ major - Haydn : Piano,

2) Sonata in D major - Mozart : Violin,

3) Musik variations on Ah! Vo us dirais-je, maman (K.265) - Mozart : Piano,

4) Symphony in C major - Mozart : Orkestra,

5) Adagio dari Divertimento - Mozart : Orkestra,

6) Rondo dari Eine Kleine Nachtmusik - Haydn : Orkestra,

7) Turkish March - Mozart : Orkestra,

8) Piano concerto in C major - Mozart : Orkestra,

9) Quartet in C major - Mozart Orkestra.

\section{METODE}

Penelitian ini merupakan penelitian kuantitatif eksperimental dengan desain eksperimen One Group Pretest-Posttest Design. Penelitian ini merupakan penelitian populasi dengan karakteristik subjek adalah siswa tunadaksa ringan yang tinggal di asrama YPAC Surakarta dengan usia 12-16 tahun. Pengumpulan data menggunakan skala psikologi yaitu skala regulasi emosi yang berjumlah 24 item dengan dua pernyataan yaitu favourable dan unfavourable dengan nilai skor dimulai dari 1 hingga 4 . Validitas skala menggunakan proffesional judgement dan uji reliabilitas menggunakan rumus alpha cronbach $(0,922)$. Analisis data menggunakan teknis statistik non parametric wilcoxon signed ranks test, dengan membandingkan hasil pretest dan posttest. 


\section{HASIL DAN PEMBAHASAN}

Analisis data menggunakan teknik uji statistik Non Parametric Wilcoxon Signed Ranks Test menghasilkan nilai sig sebesar 0,025 , nilai $\mathrm{Z}$ skore $-2,809$ dan mean rank pada saat pretest sebesar 0,00 sedangkan posttest sebesar 5,50. Berdasarkan data tersebut dapat diambil simpulan bahwa ada perubahan regulasi emosi yang cukup signifikan antara pretest dan posttest kelompok eksperimen setelah diberi perlakuan yang berupa memperdengarkan musik klasik.

Aspek perubahan kognisi mengalami perubahan drastis setelah diberi perlakuan yang ditandai dengan penurunan jumlah subjek pada kategori rendah dari persentase sebesar $60 \%$ menjadi $20 \%$ dan peningkatan jumlah subjek pada kategori sedang, dari persentase sebesar $40 \%$ menjadi $80 \%$.

Penurunan jumlah subjek pada kategori rendah dari presentase sebesar 50\% menjadi $20 \%$ dan peningkatan jumlah subjek pada kategori sedang dari presentase sebesar $50 \%$ menjadi $80 \%$ menunjukan keberhasilan pemberian musik klasik pada aspek modulasi respon.

Keberhasilan pemberian musik klasik pada aspek pemilihan situasi ditunjukan dengan adanya penurunan jumlah subjek pada kategori rendah dari persentase sebesar $70 \%$ menjadi $60 \%$, dan peningkatan jumlah subjek pada kategori sedang dari $30 \%$ menjadi $40 \%$.

Penurunan jumlah subjek pada kategori rendah dari persentase sebesar $70 \%$ menjadi $60 \%$ dan peningkatan jumlah subjek pada kategori sedang dari persentase $30 \%$ menjadi $40 \%$ menunjukan adanya pengaruh positif pemberian perlakuan terhadap aspek modifikasi situasi.

Aspek-aspek dalam regulasi emosi yang mengalami perubahan, yaitu aspek pemilihan situasi, modifikasi situasi, perubahan kognisi dan modulasi respon, sedangkan aspek penyebaran perhatian tidak mengalami perubahan. Hal ini dapat dilihat dari hasil pretest dan posttest yang tetap yaitu sebesar $50 \%$ termasuk dalam kategori yang rendah serta $50 \%$ termasuk dalam kategori sedang. Aspek penyebaran perhatian tidak mengalami perubahan disebabkan banyak hal, salah satunya adalah kurangnya pemberian perlakuan.

Hasil yang diperoleh kedua tipe strategi regulasi emosi menunjukan peningkatan setelah membandingkan data pretest dan posttest. Persentase yang diperoleh tipe antecedent focused pada kategori rendah mengalami penurunan dari $70 \%$ menjadi $60 \%$ dan pada kategori sedang mengalami peningkatan dari $30 \%$ menjadi $40 \%$. Persentase yang diperoleh tipe response focused mengalami perubahan, yaitu penurunan pada kategori rendah dari $50 \%$ menjadi $20 \%$ dan peningkatan persentase pada kategori sedang sebesar $50 \%$ menjadi $80 \%$.

Analisis data menggunakan uji wilcoxon signed ranks test menunjukan adanya perbedaan regulasi emosi sebelum diperdengarkan musik klasik dan sesudah diperdengarkan musik klasik, hal ini ditandai dengan diperolehnya nilai sig sebesar 0,025, nilai $\mathrm{Z}$ skore $-2,809$ dan mean rank pada saat pretest sebesar 0,00 sedangkan posttest sebesar 5,50. Skor yang diperoleh setelah diperdengarkan musik klasik lebih tinggi dibandingkan skor yang diperoleh sebelum memperdengarkan musik klasik, walaupun perubahan yang terjadi antara pretest dan posttest cukup signifikan, akan tetapi perubahan tersebut dimungkinkan tidak hanya berasal dari pengaruh musik klasik saja, karena dalam penelitian ini menggunakan desain penelitian eksperimen kuasi, sehingga validitas internal penelitian rendah. Peneitian ini menggunakan desain eksperimen kuasi dikarenakan jumlah subjek penelitian yang sedikit.

\section{KESIMPULAN DAN SARAN}

\section{Simpulan}

Peningkatan hasil yang diperoleh pada tingkat signifikansi 5\% saat pretest dan posttest di empat aspek regulasi emosi, antara lain aspek perubahan kognisi, modulasi respon, pemilihan situasi dan modifikasi situasi menunjukan adanya pengaruh musik klasik 
terhadap regulasi emosi tunadaksa di YPAC Surakarta. Selain itu, adanya pengaruh tersebut terlihat pada hasil analisis statistik non parametric wilcoxon signed ranks test yang memperoleh nilai sig sebesar 0,025 ; Z skor 2,809 dan mean rank pada saat pretest sebesar 0,00, sedangkan posttest sebesar 5,50.

\section{Saran}

Berdasarkan hasil penelitian dan kesimpulan, maka peneliti memberikan saransaran sebagai berikut:

a. Bagi Pihak YPAC Surakarta

Pihak YPAC lebih memaksimalkan layanan terapi yang ada, apalagi dalam terapi musik, karena selama ini pihak YPAC memberikan pelayanan terapi musik hanya kepada penyandang cacat tunaganda, autis, tunadaksa (D1) dengan tingkat sedang dan tinggi.

\section{b. Bagi Siswa}

Sebaiknya siswa YPAC Surakarta dapat terus mendengarkan musik klasik di setiap harinya, baik dalam keadaan santai ataupun pada saat melakukan kegiatan.

c. Bagi Peneliti Selanjutnya

Peneliti selanjutnya mencari subjek yang lebih banyak, sehingga dapat mengontrol variabel sekunder agar validitas internal penelitian dapat meningkat.

\section{DAFTAR RUJUKAN}

Aizid, Rizem. 2011. Sehat dan Cerdas dengan Terapi Musik. Yogyakarta:Laksana.

Anggraeni. 2008. Resiliensi pada Penyandang Tunadaksa Pasca Kecelakaan. Skripsi.Tidak diterbitkan. Universitas Gunadarma.

Akuntono, Indra. Pendidikan Anak Berkebutuhan Khusus Akan Dijamin. Online www.Kompas.com (accesed 07/15/12).

Arikunto, Suharsini. 2006. Prosedur Penelitian Suatu pendekatan Praktik. Jakarta:PT Rineka Cipta.
Astuti. 2006. Pengaruh Musik Klasik terhadap Intensitas Kunjungan Mahasiswa ke Perpustakaan Program studi Psikologi Universitas Diponegoro Semarang. Skripsi. Tidak diterbitkan. Universitas Diponegoro.

Azwar,Syaifuddin. 2009. Reliabilitas dan Validitas. Yogyakarta:Pustaka Pelajar. . 2010a. Metode penelitian. Yogyakarta:Pustaka Pelajar. - 2010b. Penyusunan Skala Psikologi. Yogyakarta:Pustaka Pelajar.

Baoe, Pono. 2003. Kamus Musik. Yogyakarta:Kanisius.

Campbell. 2002. Efek Mozart Bagi Anak-Anak. Jakarta: PT Gramedia Pustaka Utama.

Chori, Salim. 1995. Ortopedagogik Anak Tunadaksa. Jakarta:Departemen Pendidikan dan Kebudayaan.

Djohan. 2009. Psikologi Musik. Yogyakarta:GalangPress.

Efendi, Mohammad. 2008. Pengantar Psikopedagogik Anak Berkelainan. Jakarta:PT Bumi Aksara.

Gross, James. 2007. Handbook of Emotion Regulation. New York:Guilford Press.

Hadi, Sutrisno. 2002. Metodologi Research. Yogyakarta:Andi.

Holodynski dan Wolfgang. 2005. Development of Emotions and Emotion Regulation. New York: Springer.

Hude, Darwis. 2006. Emosi. Jakarta:Erlangga.

Hurlock. 1994. Perkembangan Anak Jilid 1 .Jakarta:Erlangga.

Kementrian Kesehatan RI. 2010. Pedoman Pelayanan Kesehatan Anak di Sekolah Luar Biasa (SLB) Bagi Petugas Kesehatan. Jakarta: Direktorat Jenderal Bina Kesehatan Masyarakat.

Latipun. 2010. Psikologi Eksperimen Edisi Kedua.Malang:UMMPress. 
Mangunsong, Frieda. 2009. Psikologi dan Pendidikan Anak Berkebutuhan Khusus. Jakarta: LPSP3 UI.

Monks, Nnoers dan Siti. 2002. Psikologi Perkembangan. Yogyakarta:Gadjah Mada University Press.

Ngalifah, Siti. 2010. Pengaruh Musik Klasik Terhadap Kecerdasan Emosional Anak di TK Kemala Bhayangkari 06 Glondong Tirtomani Kalasan Sleman Yogyakarta Tahun Ajaran 2009/2010. Skripsi. UIN Sunan Kalijaga Yogyakarta.

Putnam. 2005. Emotion Dysregulation and The Development of Boderline Personality Disorder. Psychopatology And Development. Cambridge University Press United States of America.899-925.

Rustriningsih. 2009. Ribuan Anak Berkebutuhan Khusus Belum Tersentuh Fasilitas Memadai. Online http://www.suaramerdekakacetak.com (accessed 19/05/11).

Satiadarma dan Roswiyani. 2004. Cerdas dengan Musik. Jakarta:Puspa Swara.

Seniati, Aries dan Bernadette. 2011. Psikologi Eksperimen. Jakarta: PT IIndeks.

Sugiyono. 2007. Statistika untuk Penelitian. Bandung;Alfabeta.

Sulistian, Chrysanty. 2007. Efek Musik dalam Terapi Wicara pada Kemampuan Verbal Anak ADHD. Thesis.Tidak diterbitkan. Universitas Katolik Soegijapranata Semarang.

Strongman. 2003. The Psychology of Emotion Fifth Edition. New Zealand:Wiley.

Tyas, Hartaris Andijaning. 2007. Seni Musik SMA. Jakarta:Erlangga.

Utami, Cicillia. 2003. Musik Klasik dan Pengaruhnya Terhadap Kreativitas Anak. Thesis. Tidak diterbitkan. Universitas Katolik Soegijapranata Semarang.

Widyaningrum, Diana Elma. 2005. Kecerdasan Emosional Pada Remaja yang Memiliki Hobi Mendengarkan Musik Klasik.
Skripsi. Tidak diterbitkan. Universitas Muhamadiyah Surakarta.

Widuri, Erlina Listyanti. 2010. Kepribadian Big Five dan Strategi Regulasi Emosi Ibu Anak ADHD (Attention Deficit Hyperactivity Disorder). Humanitas, Vol VII. 123-137.

Windura, Sutanto. 2008. Brain Mgt Series : An Absolute Genius.Jakarta : Elex Media Komputindo.

Zeelenberg, Ivan dan Nyiklicek. 2011. Emotion Regulation and Well-Being. New York: Springer. 